\title{
Recentering Shape Memory Alloy Passive Damper for Structural Vibration Control
}

\author{
Hui Qian, ${ }^{1}$ Hongnan $\mathrm{Li}^{2}{ }^{2}$ Gangbing Song, ${ }^{2,3}$ and Wei Guo ${ }^{4}$ \\ ${ }^{1}$ School of Civil Engineering, Zhengzhou University, Zhengzhou 45000, China \\ ${ }^{2}$ Faculty of Infrastructure Engineering, Dalian University of Technology, Dalian 116024, China \\ ${ }^{3}$ Department of Mechanical Engineering, University of Houston, Houston, TX 77204, USA \\ ${ }^{4}$ School of Civil Engineering, Central South University, Changsha 410075, China \\ Correspondence should be addressed to Hui Qian; qianhui@zzu.edu.cn
}

Received 12 July 2013; Accepted 9 September 2013

Academic Editor: Gang Li

Copyright (c) 2013 Hui Qian et al. This is an open access article distributed under the Creative Commons Attribution License, which permits unrestricted use, distribution, and reproduction in any medium, provided the original work is properly cited.

\begin{abstract}
This paper presents a preliminary study on the evaluation of an innovative energy dissipation system with shape memory alloys (SMAs) for structural seismic protection. A recentering shape memory alloy damper (RSMAD), in which superelastic nitinol wires are utilized as energy dissipation components, is proposed. Improved constitutive equations based on Graesser and Cozzarelli model are proposed for superelastic nitinol wires used in the damper. Cyclic tensile-compressive tests on the damper with various prestrain under different loading frequencies and displacement amplitudes were conducted. The results show that the hysteretic behaviors of the damper can be modified to best fit the needs for passive structural control applications by adjusting the pretension of the nitinol wires, and the damper performance is not sensitive to frequencies greater than $0.5 \mathrm{~Hz}$. To assess the effectiveness of the dampers for structural seismic protection, nonlinear time history analysis on a ten-story steel frame with and without the dampers subjected to representative earthquake ground motions was performed. The simulation results indicate that superelastic SMA dampers are effective in mitigating the structural response of building structures subjected to strong earthquakes.
\end{abstract}

\section{Introduction}

Conventional structures rely on their adequate stiffness, strength, and ductility to survive earthquakes. Such a design strategy may not be economical, and may be ineffective for unexpected seismic events $[1,2]$. In recent years, the design strategy based on the performance of civil structures has attached increasing attentions of both practicing engineers and structure owners [3-5]. To enhance the seismic performance of structural systems, many possible strategies have been proposed $[6,7]$, and one promising family of solutions is the passive control techniques $[8,9]$.

By and large, current passive control applications are based on the following two techniques: seismic base isolation and energy dissipation [10]. Seismic isolation system relies on special ductile alternate layers which are installed between substructure and superstructure to reduce the transfer of seismic energy to the superstructure, thus protecting the superstructure's integrity [11]. Usually, in order to limit the extent of the displacement, energy dissipation devices are incorporated into the alternate layers. Energy dissipation system incorporates special energy dissipation devices into the structures to absorb or consume a portion of the seismic energy, thereby reducing energy dissipation demand on primary structural members and minimizing possible structural damage [8]. Nowadays, several types of seismic energy dissipation devices, such as metallic dampers, friction dampers, viscoelastic dampers, and viscous fluid damper, are available. However, current technologies present some limitations, such as problems related to aging and durability, maintenance, reliability in the long run, substitution after strong events, and variable temperature-dependent performances, among others [12]. Recently, the increasing research and development of smart materials and controlling devices open up a new area for seismic vibration control of structural engineering, providing a basic platform for the design and exploration of new generation high-performance damping devices. 


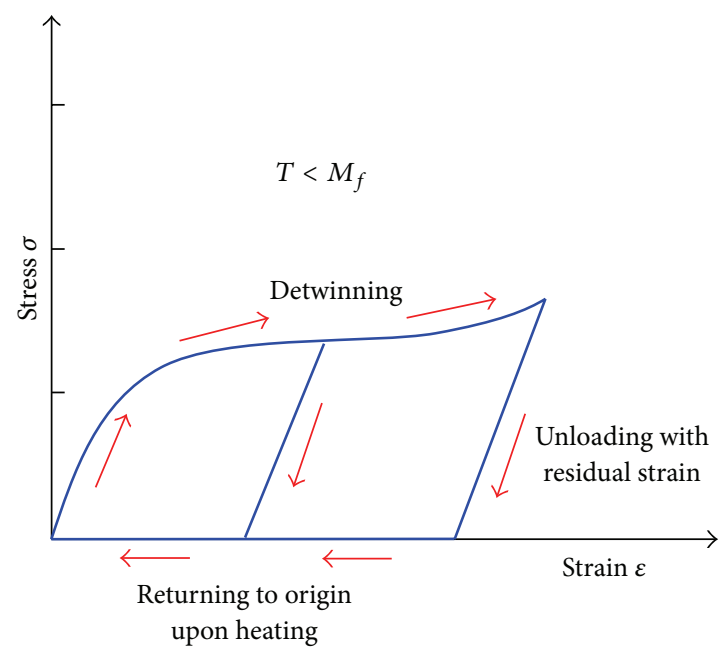

(a)

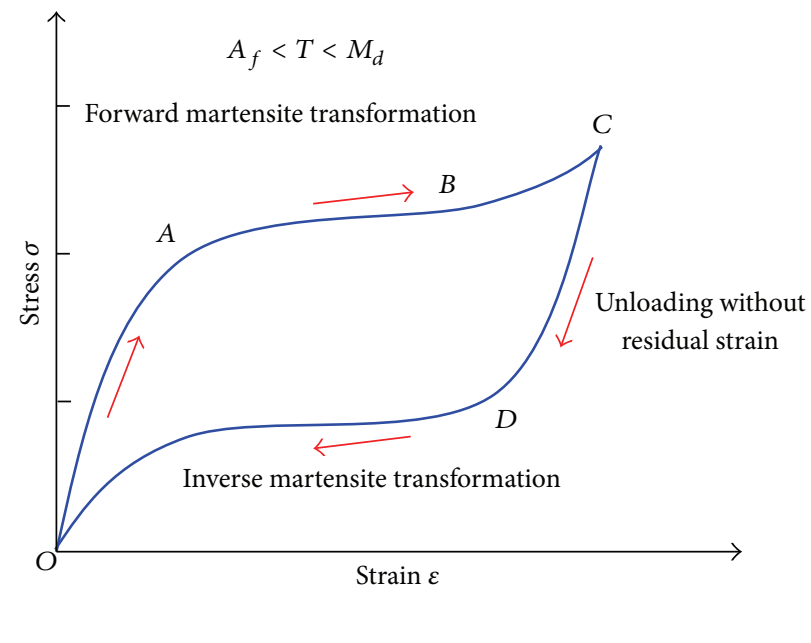

(b)

FIGURE 1: Stress-strain diagrams of NiTi shape memory alloy: (a) SME, $T<M_{f}$; (b) superelasticity, $A_{f}<T<M_{d}$.

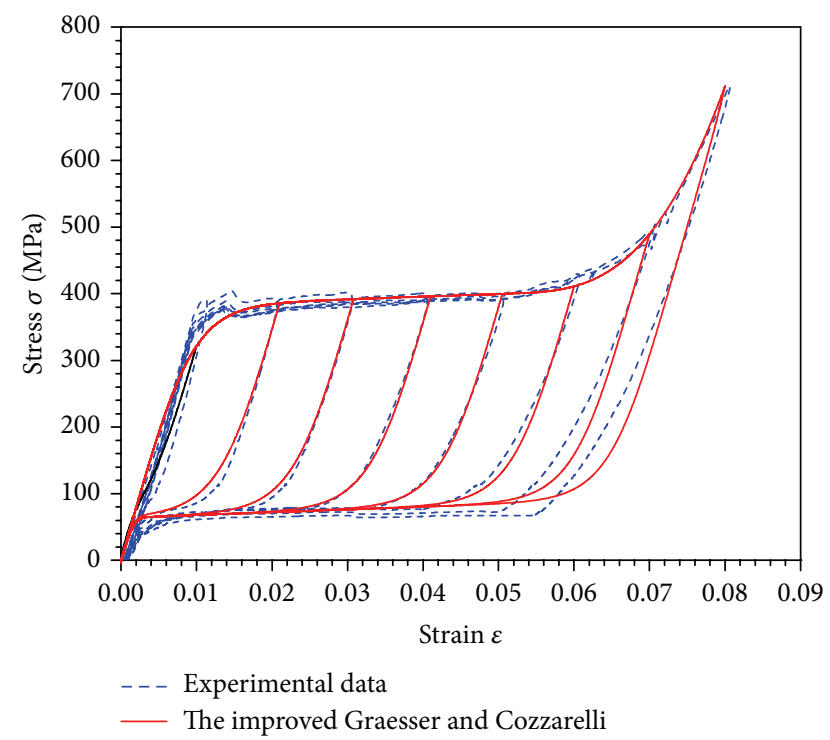

FIGURE 2: Stress-strain curves of superelastic nitinol wires.

Shape memory alloys [13] are a class of novel functional materials that possess unique properties, including shape memory effect (SME), superelasticity effect (SE), extraordinary fatigue resistance, high corrosion resistance, high damping characteristics, and temperature-dependent Young's modulus. At a low temperature, SMAs exhibit the SMEresidual deformations can be recovered by heating the material above the austenite finish temperature, as shown in Figure 1(a). At a higher temperature, SMAs exhibit the SE, as shown in Figure 1(b). In the superelastic phase, SMAs are initially austenitic. However, upon loading, stress-induced martensite is formed. Upon unloading, the martensite reverts to austenite at a lower stress level, resulting in the hysteretic behavior. These properties make them ideal candidates for seismic energy dissipation devices in structural engineering.
A significant number of research studies have been conducted in an effort to use SMAs for applications in seismic resistant design and structural retrofit in the past decade (e.g., [14-24]). Wilde et al. [14] proposed a smart isolation system combining a laminated rubber bearing with a device made of SMA for highway bridges. Their analytical results show that the isolation system can limit displacement and dissipate energy for earthquake mitigation. Dolce et al. [15] developed two families of SMA-based energy dissipating and recentering braces for seismic vibration control of buildings and bridges, as outcomes of the MANSIDE project (Memory Alloys for New Seismic Isolation and Energy Dissipation Devices). To assess the effectiveness of SMA braces to reduce the seismic response of reinforced concrete (RC) framed structures, shaking table tests of a 1/3.3-scale, threestory, two-bay RC plane frame, which was designed for low seismicity and low ductility according to the European seismic code, were carried out by Dolce et al. [16]. Their experimental results show that the SMA braces can enhance seismic performances at least comparable to those provided by steel braces, while having an additional self-centering feature. Indirli et al. [17] retrofitted historic buildings using superelastic SMA tie bars to enhance its seismic resistance capacities. DesRoches and Delemont [18] and Andrawes and Desroches [19] evaluated the efficacy of superelastic nitinol bars as restrainers to reduce the risk of collapse from unseating of bridge superstructures at the hinges. They found that the SMA bars are effective in limiting relative hinge displacements in typical multiple frame bridges. $\mathrm{Li}$ et al. [20] investigated the vibration mitigation of a stay cable provided with one superelastic SMA damper. The analytical results show that the SMA damper can reduce cable vibration significantly and the control effectiveness is influenced by SMA damper parameters and locations. Zhang and Zhu [21] developed reusable hysteretic damper (RHD) based on superelastic nitinol stranded wires, and their numerical analysis indicated the effectiveness of RHD 


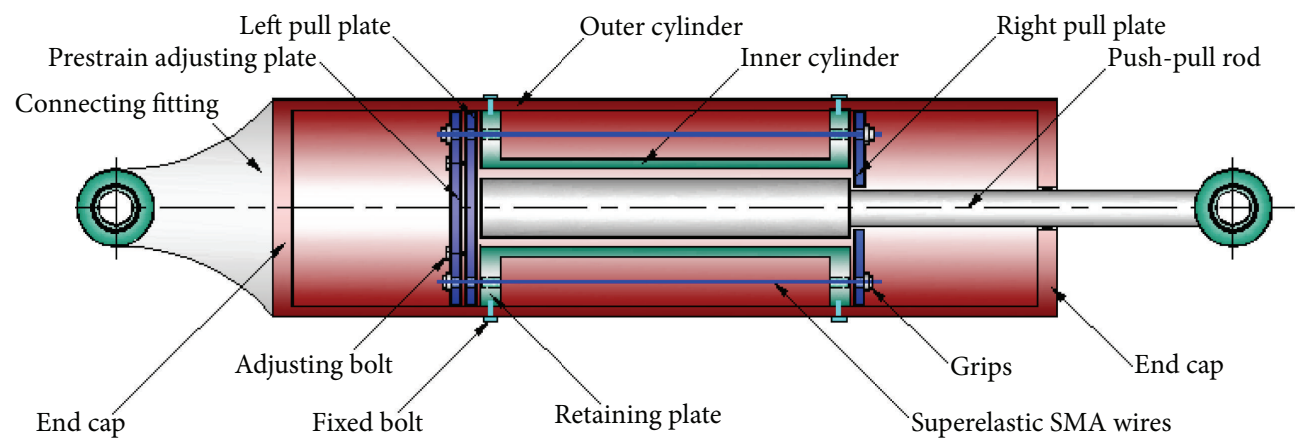

FIgURE 3: Diagram of RSMAD.

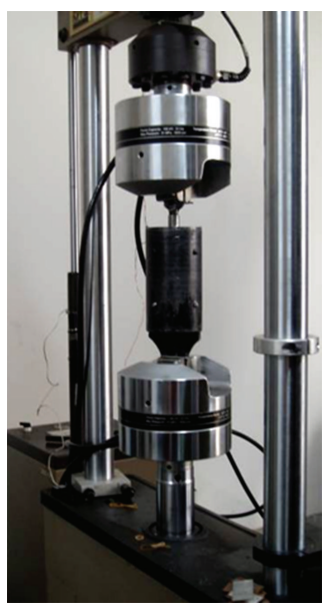

Figure 4: Photograph of experimental setup.

in passive seismic response control of structures. Ocel et al. [22] and McCormick et al. [23] investigated beam-column connections using SMA bars. Their studies show that SMA can enhance the seismic performance of the connections. Parulekar et al. [24] proposed a damper device using austenite NiTi wires. The device is tested and validated using a thermomechanical model of SMA taking into account the residual martensite accumulation. Performance of the structure with SMA dampers is compared with that of the same structure with yielding dampers.

Previous works show that SMAs are of promise in structural engineering, particularly as energy dissipation components for seismic protection. However, significant research is still needed. In Particular, designing new types of SMAbased passive seismic devices, which possess not only energy dissipation and recentering capabilities but also simple configuration for easy installation in the practical engineering, is still a challenge.

This paper presents an innovative recentering shape memory alloy damper (RSMAD) for seismic structural protection. The damper is simple in design and easy to implement. Superelastic nitinol wires were utilized in the damper as kernel energy dissipating components. Cyclic tensilecompressive tests on the damper model with various prestrain under different loading frequencies and displacements were conducted. To assess the effectiveness of the damper for structural seismic protection, nonlinear time history analyses on a ten-story steel frame subjected to representative earthquake ground motions, with and without the dampers, were performed.

\section{Constitutive Equation of Superelastic SMA Wire}

With the wide applications of SMAs in different fields, modeling of the peculiar mechanical behavior of SMAs, such as SME and superelasticity, has been an active area of research over the past decades. So far, many constitutive models for SMA have been developed [25-33]. These models describe the thermomechanical, thermoelectrical, and thermochemical behaviors of SMAs; however, most of them are too complex to be convenient for practical application in earthquake engineering. In this paper, a relatively simple model developed by Graesser and Cozzarelli [34] is adopted. This model is an extension of a one-dimensional strain rate independent model for hysteretic behavior proposed by Özdemir [35]. The equation is given as

$$
\dot{\sigma}=E\left[\dot{\varepsilon}-|\dot{\varepsilon}|\left(\frac{\sigma-\beta}{Y}\right)^{n}\right],
$$

where $\sigma$ and $\varepsilon$ are the one-dimensional stress and the onedimensional strain, respectively; $E$ is the initial elastic modulus; $Y$ is the yield stress; $n$ is a constant assumed any positive odd real value controlling the sharpness of transition from the elastic state to the phase transformation; $\dot{\sigma}$ and $\dot{\varepsilon}$ denote the time derivative of the stress and strain, respectively; and $\beta$ is the one-dimensional back stress, given by

$$
\beta=E \alpha\left\{\varepsilon_{\text {in }}+f_{T}|\varepsilon|^{c} \operatorname{erf}(a \varepsilon)[u(-\varepsilon \dot{\varepsilon})]\right\},
$$

where $f_{T}, a$, and $c$ are material constants controlling the type and size of the hysteresis, the amount of elastic recovery during unloading, and the slope of the unloading stress plateau, respectively. When $f_{T}=0$, the model is purely martensitic. When $f_{T}>0$, the model predicts the superelastic behavior. $\alpha$ is a constant controlling the slope of the $\sigma-\varepsilon$ curve in the inelastic range, given by

$$
\alpha=\frac{E_{y}}{E-E_{y}},
$$

where $E_{y}$ is the slope of the $\sigma-\varepsilon$ curve in the inelastic range. 


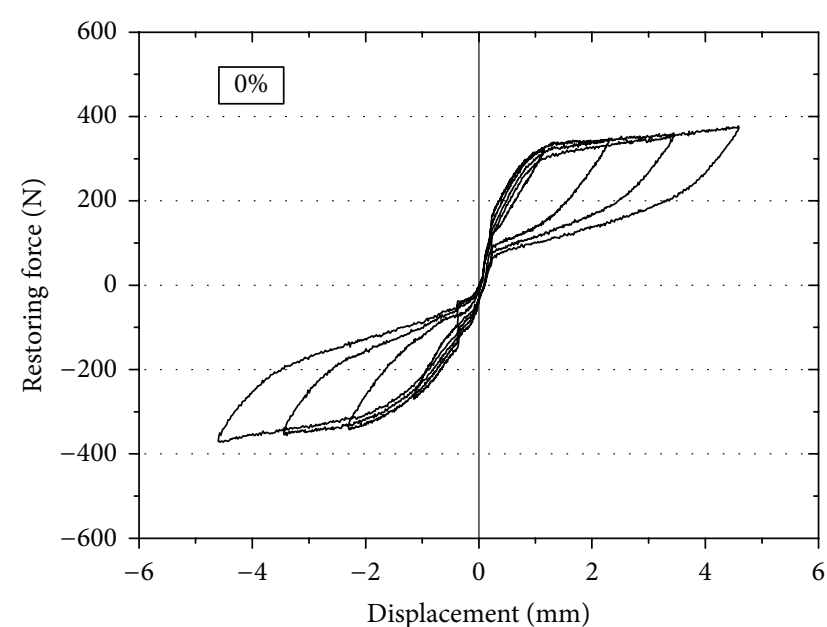

(a)

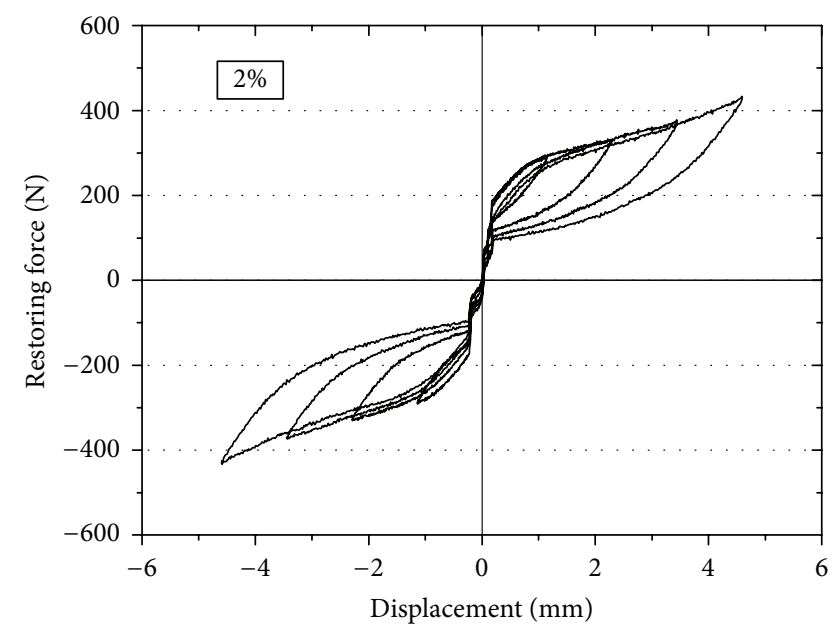

(c)

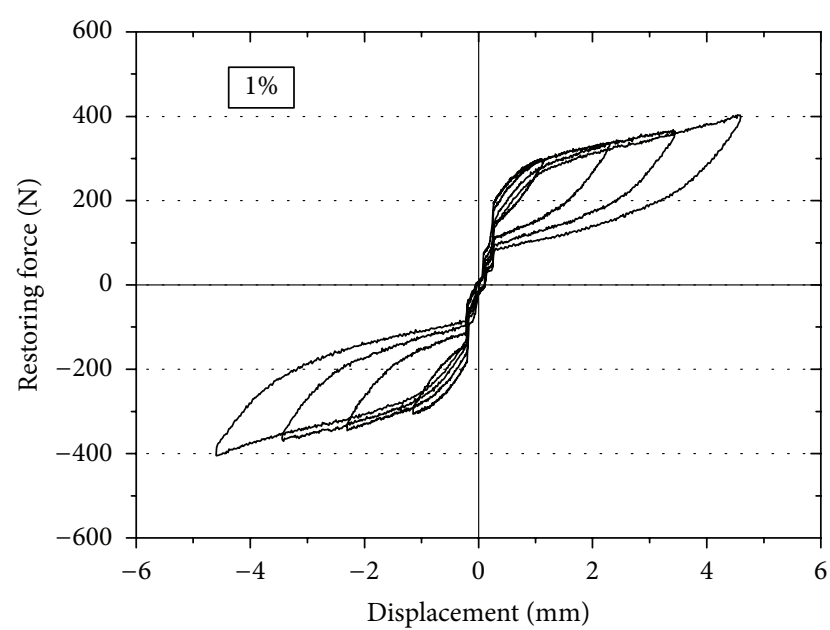

(b)

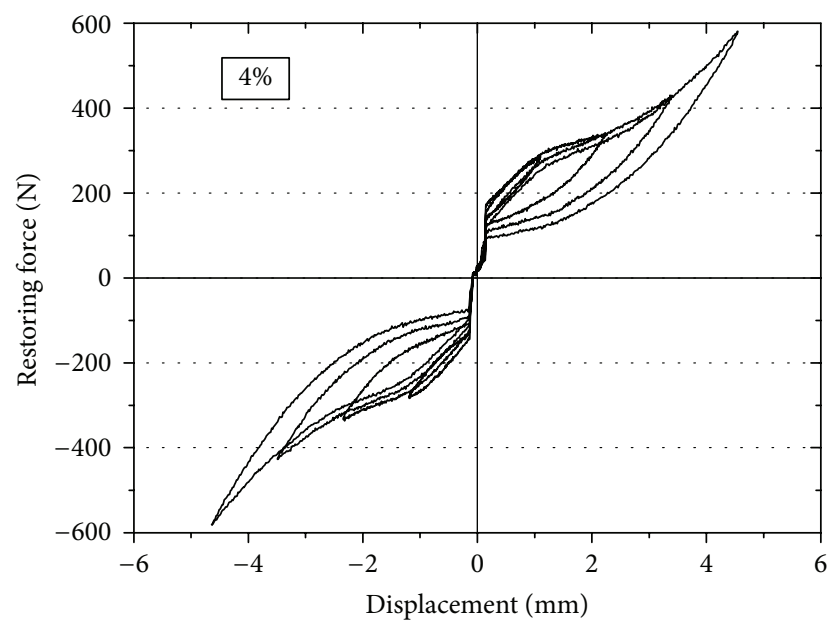

(d)

FIGURE 5: Hysteresis loops of the RSMAD at different prestrains and displacement amplitudes $\left(0.05 \mathrm{~Hz}\right.$ frequency of loading, $20^{\circ} \mathrm{C}$ temperature).

$\varepsilon_{\text {in }}$ is the inelastic strain, given by

$$
\varepsilon_{\text {in }}=\varepsilon-\frac{\sigma}{E} .
$$

$u()$ is the unit step function, defined as

$$
u(x)= \begin{cases}+1 & x \geq 0 \\ 0 & x<0\end{cases}
$$

$\operatorname{erf}()$ is the error function, defined by

$$
\operatorname{erf}(x)=\frac{2}{\sqrt{\pi}} \int_{0}^{\pi} e^{-t^{2}} d t
$$

The original Graesser and Cozzarelli model has a relatively simple expression with the parameters that can be easily acquired; however, this model excludes the martensitic hardening characteristics of SMAs under large amplitudes, which are critical for structural safety protection under extreme events.
To overcome the limitation of the original model, Wilde et al. [14] extended the Graesser and Cozzarelli model by dividing the full loop into four parts, adding two terms with six parameters into (1). The Wilde model was utilized to simulate the cyclic behaviors of SMA devices in other researches [21].

In the following, in order to accurately predict the cyclic behavior of a superelastic SMA device, especially capture the martensitic hardening characteristics of SMAs under large amplitudes, an improved Graesser and Cozzarelli model is presented. In the present model, the backstress expression is modified by adding a special term to capture the martensitic hardening characteristic of SMA under large amplitudes. The modified model is of the form

$$
\begin{aligned}
& \dot{\sigma}=E\left[\dot{\varepsilon}-|\dot{\varepsilon}|\left(\frac{\sigma-\beta}{Y}\right)^{n-1}\left(\frac{\sigma-\beta}{Y}\right)\right], \\
& \beta=E \alpha\left\{\varepsilon_{\text {in }}+f_{T}|\varepsilon|^{c} \operatorname{erf}(a \varepsilon)[u(-\varepsilon \dot{\varepsilon})]\right.
\end{aligned}
$$




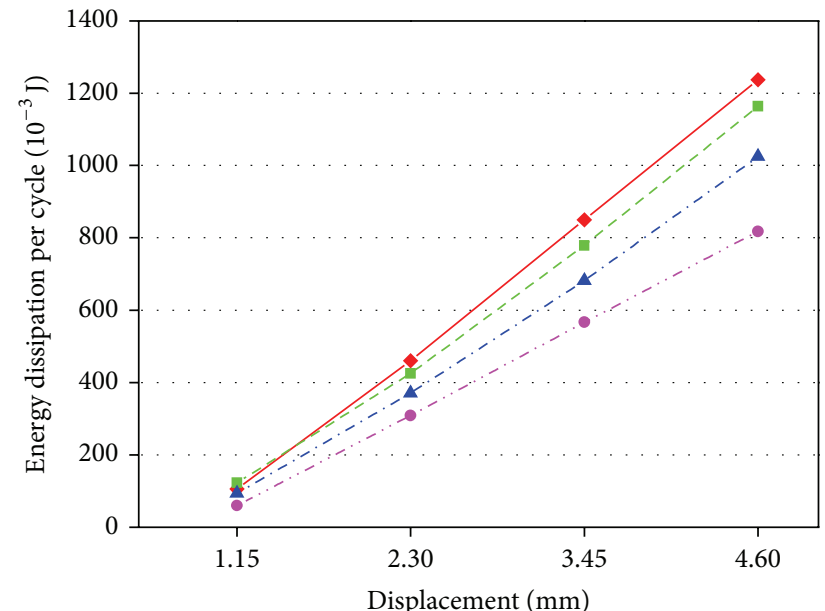

(a)

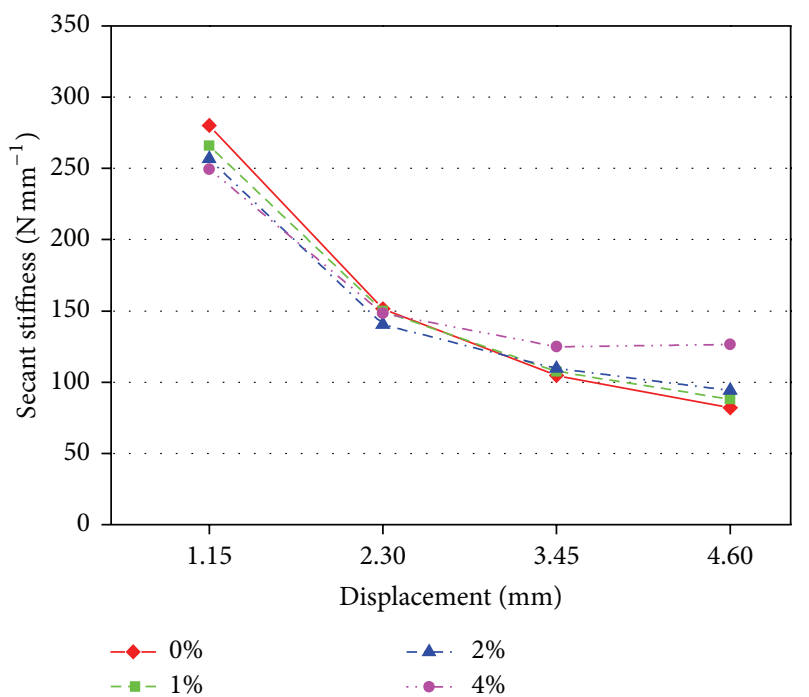

(c)

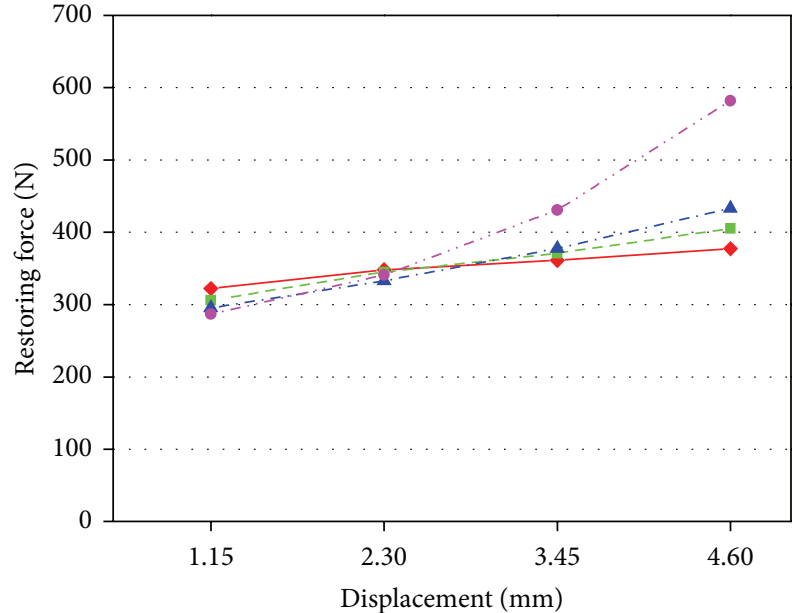

(b)

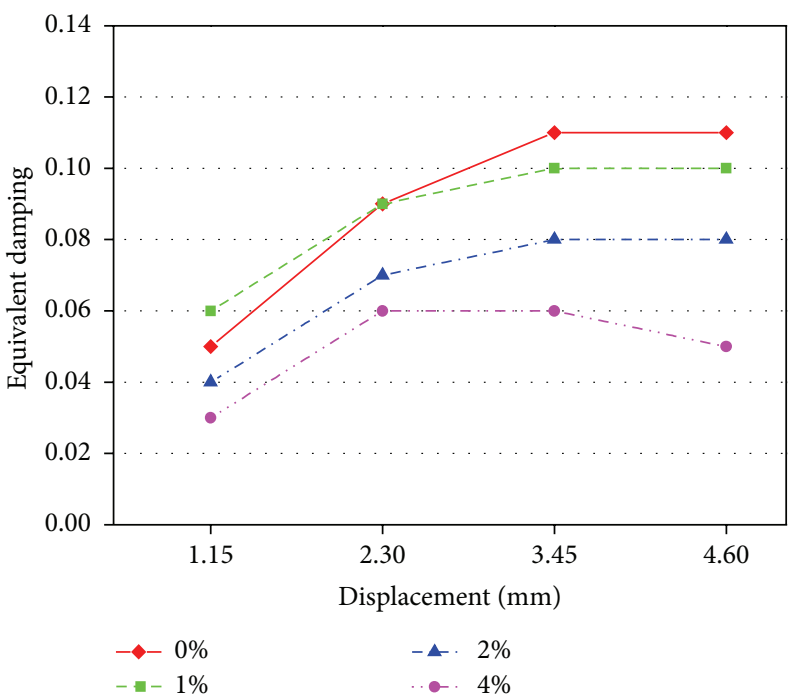

(d)

FIGURE 6: Mechanical properties of RSMAD as a function of prestrain and displacement amplitude $\left(0.05 \mathrm{~Hz}\right.$ frequency of loading, $20^{\circ} \mathrm{C}$ temperature).

$$
\begin{aligned}
& +f_{M}\left[\varepsilon-\varepsilon_{\mathrm{Mf}} \operatorname{sgn}(\varepsilon)\right]^{m}[u(\varepsilon \dot{\varepsilon})] \\
& \left.\times\left[u\left(|\varepsilon|-\varepsilon_{\mathrm{Mf}}\right)\right]\right\}
\end{aligned}
$$

The third term in (2) is used to contribute to the backstress on the ascending branch of the hysteresis in a way that allows for the martensitic hardening. $\varepsilon_{\mathrm{Mf}}$ is the martensite finish strain, $f_{M}$ and $m$ are material constants controlling the martensitic hardening curve. $\operatorname{sgn}(x)$ is the signum function, given by

$$
\operatorname{sgn}(x)= \begin{cases}+1 & x>0 \\ 0 & x=0 \\ -1 & x<0\end{cases}
$$

Figure 2 shows the stress-strain curves of superelastic nitinol wires predicted by the improved Graesser and Cozzarelli model versus experimental data at different strain levels. The characteristic parameters used in the models are $E=39500 \mathrm{MPa}, Y=385 \mathrm{MPa}, \alpha=0.01, f_{T}=1.14$, $c=0.001, a=550, n=3, \varepsilon_{\mathrm{Mf}}=0.05, f_{M}=42500$, and $m=3$. The superelastic nitinol wires are $0.5 \mathrm{~mm}$ in diameter, with a composition of approximately $50.9 \% \mathrm{Ni}$ and 49.1\% Ti. Under zero external stress, the martensite start and finish temperatures $\left(M_{f}, M_{s}\right)$ and the austenite start and finish temperatures $\left(A_{s}, A_{f}\right)$, measured by differential scanning calorimeter (DSC), are $-73^{\circ} \mathrm{C},-55^{\circ} \mathrm{C},-23^{\circ} \mathrm{C}$, and $5^{\circ} \mathrm{C}$, respectively. The uniaxial tension test of the superelastic nitinol wires was carried out using an electromechanical universal testing machine at room temperature of $20^{\circ} \mathrm{C}$. The nitinol wire samples, with a $100 \mathrm{~mm}$ test length between the two custom-made grips, were subjected to triangular cyclic loading under different strain amplitudes. The strains were calculated from the elongation measured by a $50 \mathrm{~mm}$ gage length extensometer with the stress calculated from the axial force, which was measured by a $10 \mathrm{KN}$ load cell. Prior to 


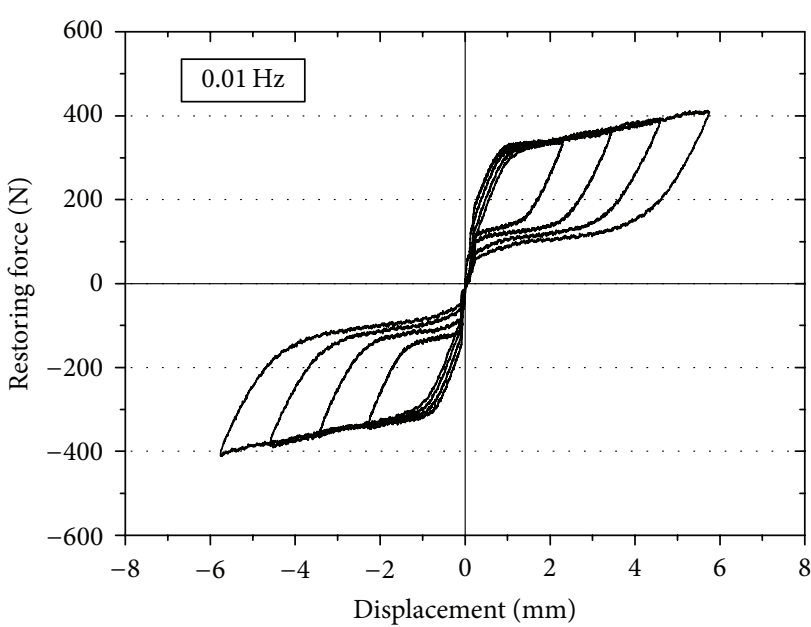

(a)

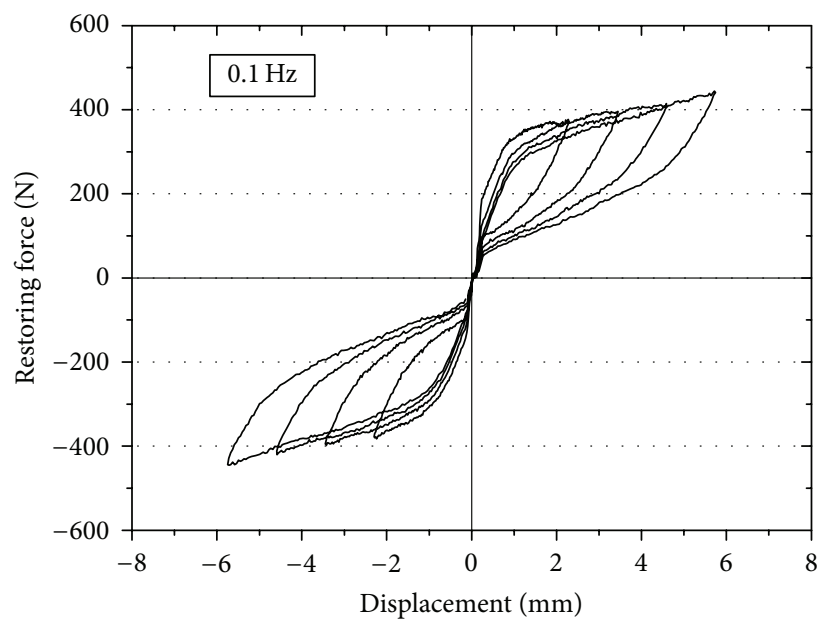

(c)

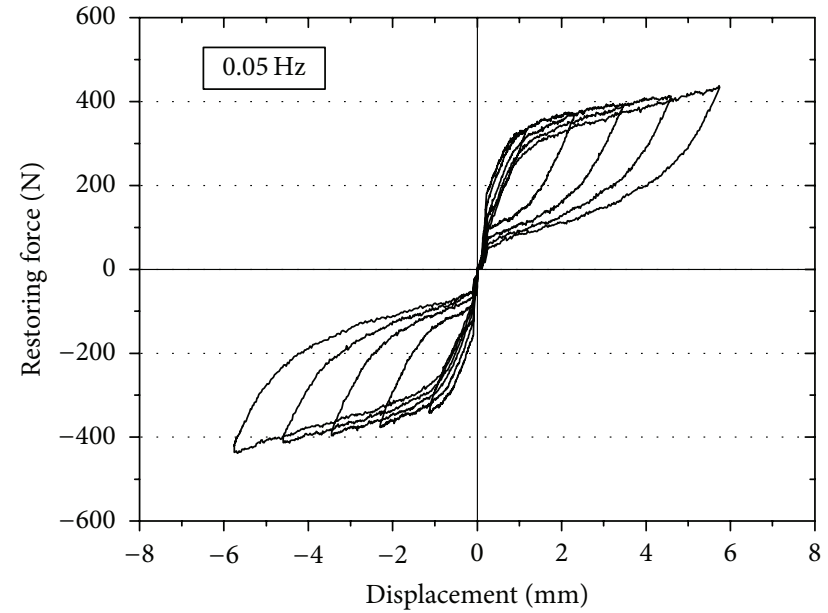

(b)

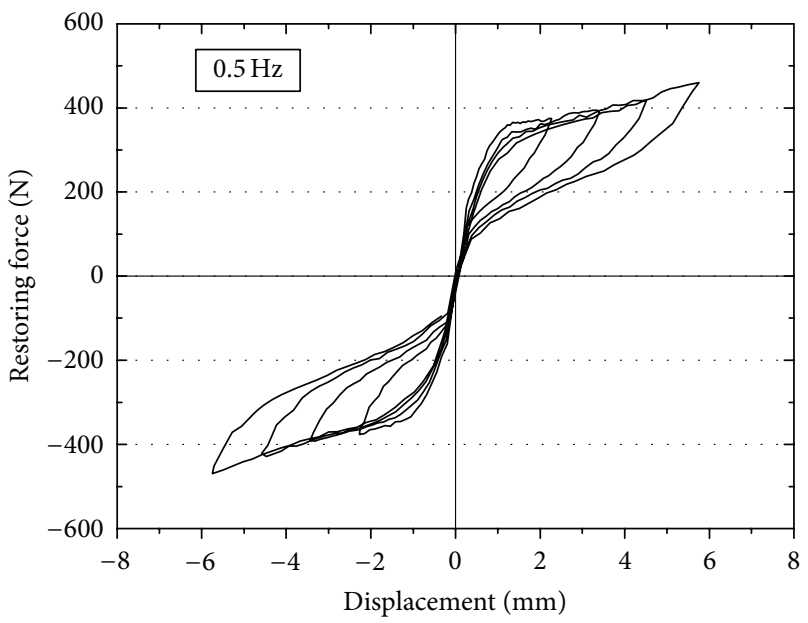

(d)

FIGURE 7: Hysteresis loops of the RSMAD at different loading frequencies and displacement amplitudes $\left(0.6 \mathrm{~mm}\right.$ predisplacement, $20^{\circ} \mathrm{C}$ temperature).

testing, the nitinol SMA specimens were cycled 20 times at $6 \%$ strain amplitude and $1.2 \times 10^{-3} \mathrm{~s}^{-1}$ strain rate by a "training" process to reach a steady-state condition. The experimental data in Figure 2 are the results of cyclic tests on the superelastic nitinol wire at $1.2 \times 10^{-3} \mathrm{~s}^{-1}$ strain rate with $1 \%$ to $8 \%$ strain levels. As shown in Figure 2, the hysteresis loops based on the improved Graesser and Cozzarelli model and experimental data match with close accuracy. Moreover, the improved model can accurately reflect the martensitic hardening characteristic of SMAs under large amplitudes.

\section{An Innovative SMA Damper: Design, Experiment, and Numerical Simulation}

3.1. Recentering SMA Damper Design. By utilizing the energy dissipating and recentering features of superelastic nitinol SMA, an innovative damper is designed. As shown in Figure 3, the damper consists of outer and inner cylinders, left and right pull plates, superelastic SMA wires, retaining plate, prestrain adjusting plate, adjusting bolt, fixed bolt, push-pull rod, grip, end caps, and connecting fitting. In this damper, superelastic nitinol wires are the key components that provide both damping and self-centering abilities.

The damper will be connected to a structure via its pushpull rod and the connecting fitting. The prestrain of the superelastic wires can be adjusted by the prestrain adjusting plate and the adjusting bolt. The configuration of the damper shown in Figure 3 is in its equilibrium position. The specific design of the damper allows the push-pull rod to move in both left and right directions and return to its equilibrium position when the load is removed (self-centering). During this cyclic process, the damper provides damping, attributed to the hysteretic property of the superelastic wires.

\subsection{Experimental Tests}

3.2.1. Setup and Program. An SMA damper based on the design presented in Section 3.1 is fabricated. To assess the performance of the SMA damper, cyclic tests were carried 


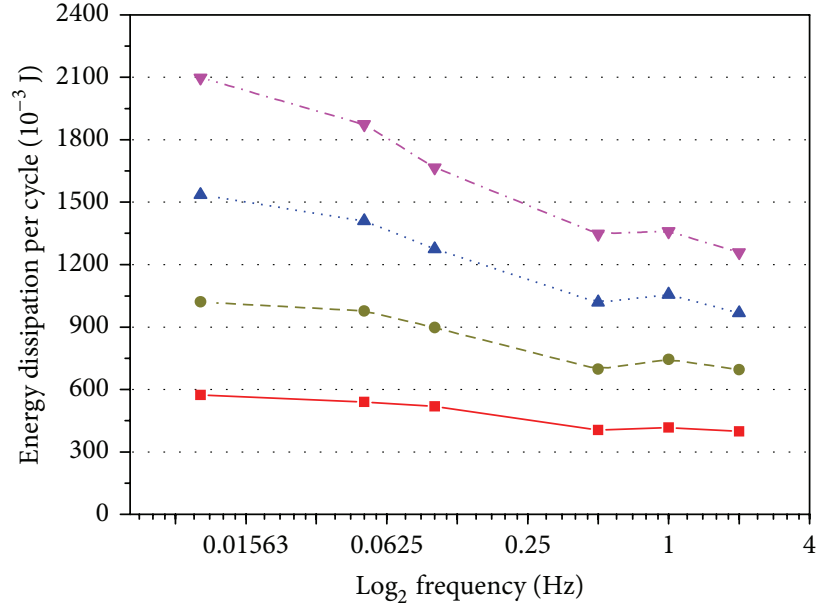

(a)

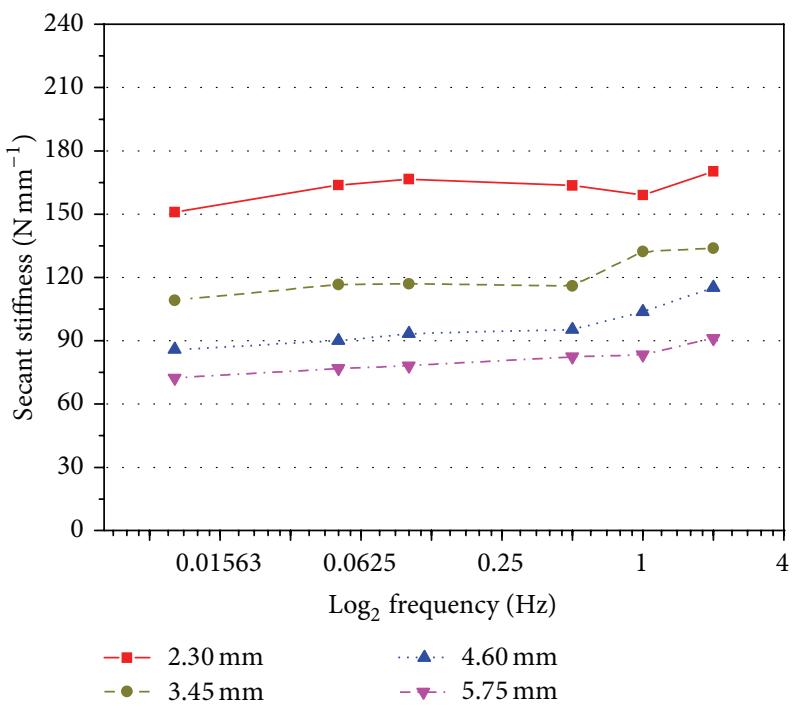

(c)

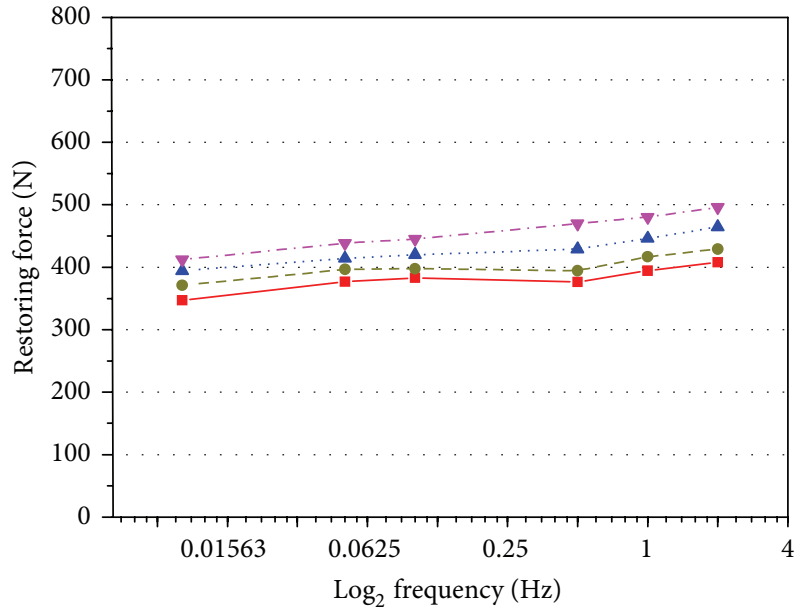

(b)

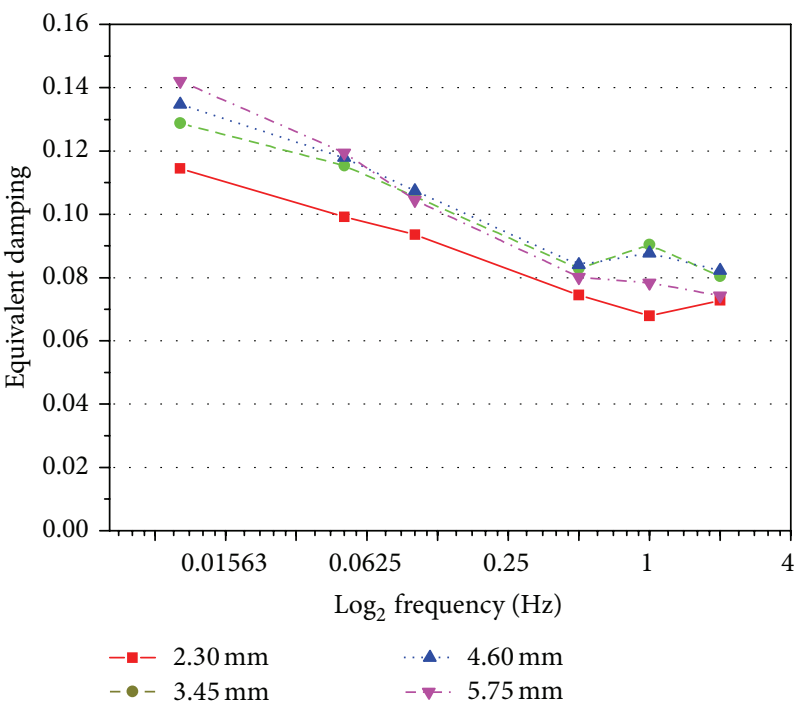

(d)

FIGURE 8: Mechanical properties of RSMAD as a function of loading frequencies and displacement amplitudes $(0.6 \mathrm{~mm}$ predisplacement, $20^{\circ} \mathrm{C}$ temperature).

out. The SMA damper is $210 \mathrm{~mm}$ in length with a diameter of $100 \mathrm{~mm}$ and a stroke of $\pm 9.2 \mathrm{~mm}$ (the maximum allowable strain for superelastic nitinol wires is $8 \%$ ). Four superelastic nitinol wires of a length of $115 \mathrm{~mm}$ and a diameter of $0.5 \mathrm{~mm}$ are used.

Tests were conducted using an MTS 810 machine with a $100 \mathrm{KN}$ load cell at room temperature of $20^{\circ} \mathrm{C}$. The layout of the test system is shown in Figure 4. The damper was tested with different prestrains, at different loading frequencies and at various amplitudes. During the tests, both force and displacement are recorded.

Prior to the installation, each nitinol wire was cycled 20 times at $6 \%$ strain with $1.2 \times 10^{-3} \mathrm{~s}^{-1}$ strain rate to minimize the accumulation of residual strain and reach a steady-state condition. The scheme of the tests is described as follows.

(1) Without prestrain, the damper was subjected to cyclic loading at $0.05 \mathrm{~Hz}$ frequency with displacement amplitudes of $2.3 \mathrm{~mm}$ ( $2 \%$ of total length), $3.45 \mathrm{~mm}$ ( $3 \%$ of total length), and $4.6 \mathrm{~mm}$ ( $4 \%$ of total length), respectively.

(2) Step (1) was repeated with prestrains of $1 \%(1.15 \mathrm{~mm}$ predisplacement), $2 \%$ ( $2.3 \mathrm{~mm}$ predisplacement), and $4 \%$ (4.6 $\mathrm{mm}$ predisplacement), respectively.

(3) With $0.5 \%$ prestrain (about $0.6 \mathrm{~mm}$ predisplacement), the damper was subjected to cyclic loading at $0.01 \mathrm{~Hz}$ loading frequency with displacement amplitudes of $2.3 \mathrm{~mm}, 3.45 \mathrm{~mm}, 4.6 \mathrm{~mm}$, and $5.75 \mathrm{~mm}$, respectively.

(4) Step (3) was repeated with loading frequencies of $0.05 \mathrm{~Hz}, 0.1 \mathrm{~Hz}, 0.5 \mathrm{~Hz}, 1 \mathrm{~Hz}$, and $2 \mathrm{~Hz}$, respectively.

To describe the performance of RSMAD as a function of prestrains, loading frequencies, and displacement amplitudes, some important mechanical properties were calculated, including the secant stiffness, $K_{s}$, the energy dissipation 


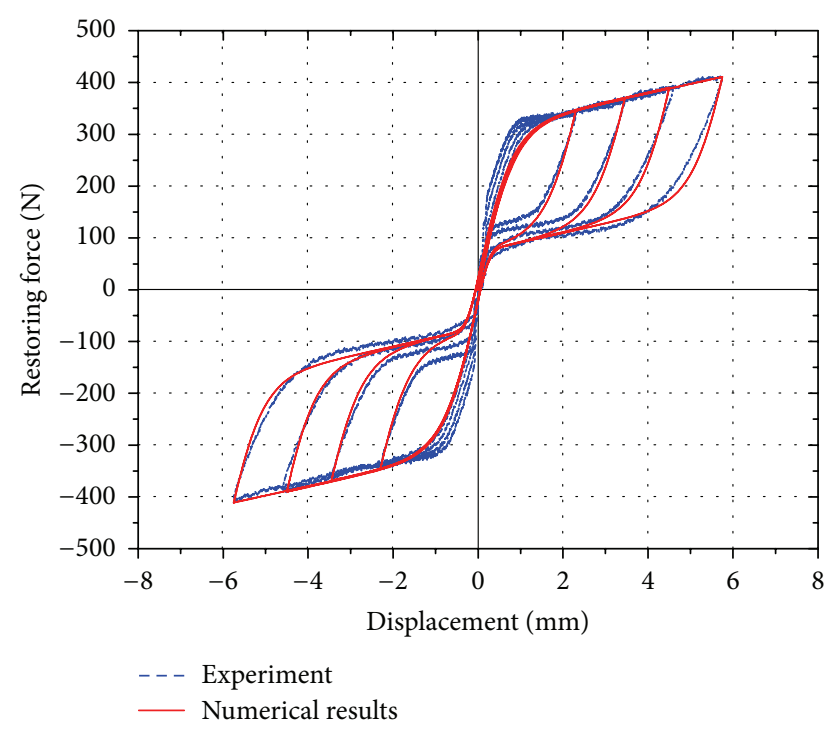

FIGURE 9: Comparison between experimental and numerical fitting curves of RSMAD.

per cycle, $W_{D}$, the restoring force at peak displacement per cycle, $F_{d}$, and the equivalent viscous damping ratio, $\xi_{\text {eq }}$, which is expressed as

$$
\xi_{\mathrm{eq}}=\frac{W_{D}}{2 \pi K_{s} \delta^{2}},
$$

where $\delta$ is the displacement amplitude of the cycle.

3.2.2. Experimental Results. Figure 5 shows the hysteresis loops of RSMAD at different prestrains and displacement amplitudes. The tests were carried out at $0.05 \mathrm{~Hz}$ frequency of loading and room temperature of $20^{\circ} \mathrm{C}$. As seen from Figure 5, the SMA damper shows double-flag hysteretic behavior without any residual strain.

Figure 6 shows the mechanical properties of RSMAD as a function of prestrain and displacement amplitude. As we can see in Figure 6, the greater the amplitude is, the greater the energy dissipation per cycle and restoring force are. However, the secant stiffness reduces markedly while increasing the amplitude. With the increasing of the predisplacement, the energy dissipation per cycle decreases, and restoring force and the secant stiffness increase at large displacement. The effectiveness of a damper is generally measured by the equivalent viscous damping ratio. With the increasing of the predisplacement, the equivalent damping ratio reduces. The most important finding is that when the predisplacement is less than $2.3 \mathrm{~mm}$ ( $2 \%$ prestrain), the equivalent damping ratio increased with the increasing of the amplitude; however, when the predisplacement is $4.6 \mathrm{~mm}$ ( $4 \%$ prestrain), the maximum of the equivalent damping ratio is at $2.3 \mathrm{~mm} \mathrm{(2 \%}$ prestrain). This is because the maximum of the equivalent damping ratio of the NiTi SMA specimens is at about $6 \%$ total strain, as noted in [10].

Figure 7 shows the hysteresis loops of RSMAD with $0.6 \mathrm{~mm}$ predisplacement at different loading frequencies and displacement amplitudes at the temperature of $20^{\circ} \mathrm{C}$. Figure 8 shows mechanical properties of RSMAD as a function of frequency of loading and displacement amplitude. As we can see in Figures 7 and 8, the energy dissipation per cycle and the equivalent damping decrease as the loading frequency increases in the range of $0.01-0.5 \mathrm{~Hz}$ but are not much sensitive to frequencies greater than $0.5 \mathrm{~Hz}$. The restoring force and the secant stiffness increase slightly as the loading frequency increases in the total range of experimental frequency.

3.3. Numerical Simulation. Based on the improved Graesser and Cozzarelli model of SMA wire, a theoretic model of the SMA damper is developed. The differential equations of the model are given as

$$
\begin{aligned}
\dot{F}=K_{0}\left[\dot{x}-|\dot{x}|\left|\frac{F-B}{B_{c}}\right|^{(n-1)}\left(\frac{F-B}{B_{c}}\right)\right] \\
B=K_{0} \alpha\left\{x_{\mathrm{in}}+f_{T}|x|^{c} \operatorname{erf}(a x)[u(-x \dot{x})]\right. \\
+f_{M}\left[x-x_{\mathrm{Mf}} \operatorname{sgn}(x)\right]^{m} \\
\left.\times[u(x \dot{x})]\left[u\left(|x|-x_{\mathrm{Mf}}\right)\right]\right\},
\end{aligned}
$$

where $F$ is restoring force; $x$ is displacement; $B$ is back-force; $K_{0}$ is initial stiffness; $B_{c}, \alpha, f_{T}, n, a, c, x_{\mathrm{Mf}}, f_{M}$, and $m$ and are constants controlling the size of the hysteresis loop; $x_{\text {in }}$ is the inelastic displacement and $x_{\text {in }}=x-F / K_{0} ; \operatorname{erf}(x), u(x)$, and $\operatorname{sgn}(x)$ are, respectively, the error function, the step function, and the signum function, which have already been listed in Section 2.

Figure 9 shows the comparison of experimental results with numerical prediction based on the theoretical model at different displacement amplitudes. The parameters of the constitutive equation used in this study to simulate the behaviors of RSMAD are given as follows: $K_{0}=380 \mathrm{~N} / \mathrm{mm}, B_{c}=$ $330 \mathrm{~N}, \alpha=0.05, f_{T}=21, c=0.0001, a=3, n=2$, $x_{\mathrm{Mf}}=5.75 \mathrm{~mm}, f_{M}=42500$, and $m=3$. To accurately simulate the hysteresis behavior, the above parameters were directly obtained from the cyclic test results of the SMA damper according to the parameters' meanings and roles. The values also can be converted through the section area and the length of NiTi wires. However, there is slight difference between the two parameter groups. This is possible because of the effect of loading conditions on the cyclic behavior of $\mathrm{NiTi}$ wires. As can be seen in Figure 9, numerical predictions agree well with the experimental results.

Table 1 shows the comparison of the experimental data and numerical results, respectively, of the energy dissipation per cycle, the secant stiffness, and the equivalent viscous damping. As can be seen in Table 1, the maximum differences of energy dissipation per cycle, secant stiffness, and equivalent viscous damping are $5.0 \%, 1.2 \%$, and, $5.1 \%$, respectively. These results indicate that the mechanical behavior of the SMA damper is well predicted by the numerical model, which verifies its suitability for the damper. 


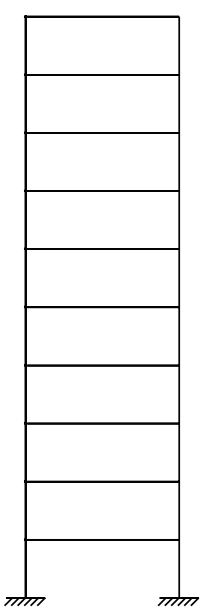

(a) Bare structure

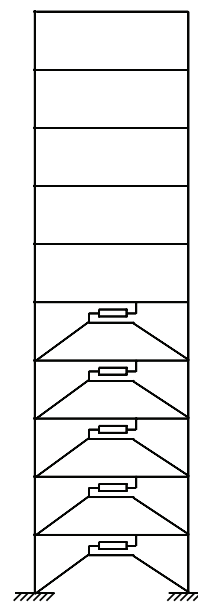

(b) Case 1

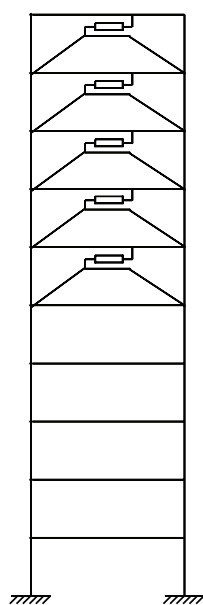

(c) Case 2

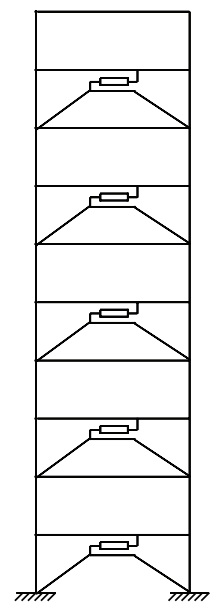

(d) Case 3

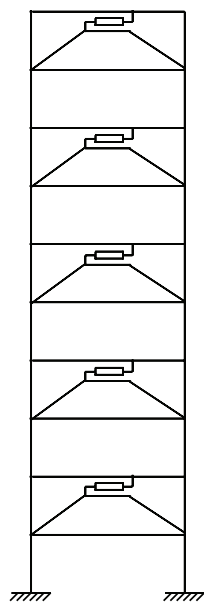

(e) Case 4

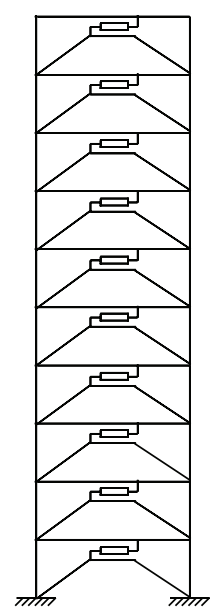

(f) Case 5

FIgURE 10: Different cases of the ten-story frame structure.

TABLE 1: Comparison between the experimental and theoretical results.

\begin{tabular}{|c|c|c|c|c|c|c|c|c|c|}
\hline \multirow{2}{*}{$\begin{array}{l}\text { Peak } \\
\text { displacement } \\
(\mathrm{mm})\end{array}$} & \multicolumn{3}{|c|}{ Energy dissipation per cycle $(\mathrm{N} \cdot \mathrm{mm})$} & \multicolumn{3}{|c|}{ Secant stiffness $(\mathrm{N} / \mathrm{mm})$} & \multicolumn{3}{|c|}{ Equivalent viscous damping (\%) } \\
\hline & $\begin{array}{c}\text { Experimental } \\
\text { data }\end{array}$ & $\begin{array}{l}\text { Numerical } \\
\text { results }\end{array}$ & Difference & $\begin{array}{c}\text { Experimental } \\
\text { data }\end{array}$ & $\begin{array}{l}\text { Numerical } \\
\text { results }\end{array}$ & Difference & $\begin{array}{c}\text { Experimental } \\
\text { data }\end{array}$ & $\begin{array}{l}\text { Numerical } \\
\text { results }\end{array}$ & Difference \\
\hline 2.3 & 573.90 & 545.00 & $5.0 \%$ & 150.90 & 150.44 & $0.3 \%$ & 11.40 & 10.90 & $4.4 \%$ \\
\hline 3.4 & 1021.10 & 1026.81 & $0.6 \%$ & 109.17 & 108.27 & $0.8 \%$ & 12.80 & 13.06 & $2.0 \%$ \\
\hline 4.6 & 1534.70 & 1586.28 & $3.4 \%$ & 85.77 & 84.78 & $1.2 \%$ & 13.40 & 14.08 & $5.1 \%$ \\
\hline 5.7 & 2097.80 & 2099.43 & $0.1 \%$ & 72.37 & 71.92 & $0.6 \%$ & 14.20 & 14.30 & $0.7 \%$ \\
\hline
\end{tabular}

TABLE 2: Parameters of the structure.

\begin{tabular}{lcccccc}
\hline $\begin{array}{l}\text { Story height } \\
h(\mathrm{~m})\end{array}$ & $\begin{array}{c}\text { Story mass } \\
m(\mathrm{~kg})\end{array}$ & $\begin{array}{c}\text { Story initial } \\
\text { stiffness } \\
k_{\mathrm{s}}(\mathrm{kN} / \mathrm{mm})\end{array}$ & $\begin{array}{c}\text { Story yield shear } \\
Q_{\text {sy }}(\mathrm{kN})\end{array}$ & $\begin{array}{c}\text { Story yield } \\
\text { displacement } \\
d_{\text {sy }}(\mathrm{mm})\end{array}$ & $\begin{array}{c}\text { Inelastic } \\
\text { stiffness ratio } \\
\gamma\end{array}$ & $\begin{array}{c}\text { Damping ratio } \\
Z\end{array}$ \\
\hline $4 \mathrm{~m}$ & $64 \times 10^{3}$ & 40 & 400 & 10 & 0.01 & $2 \%$ \\
\hline
\end{tabular}

\section{Model of Structure with SMA Dampers}

The main objective of including energy dissipating devices in a structure is to reduce structural response through energy dissipation. To protect the original structural members under strong seismic loading, nonlinear deformation in energy dissipating devices will be allowed. In frame structures, the devices are usually incorporated in steel braces connecting two consecutive stories of the building. The dynamic response of the structure subjected to earthquake loading is governed by the following equation:

$$
M_{s} \ddot{x}(t)+C_{s} \dot{x}(t)+F_{s}(x(t))+F_{d}(x(t))=-M_{s} I \ddot{x}_{g}(t),
$$

where $M_{s}$ is the mass matrix, $C_{s}$ is the damping coefficient matrix, $F_{s}$ is the vector of the frames restoring force, and $F_{d}$ is the vector of restoring force resulting from SMA dampers. The $x, \dot{x}$, and $\ddot{x}$ are the structural displacement, velocity, and acceleration vectors, respectively. On the right-hand side of the equation, the vector $I$ is the influence vector and the vector $\ddot{x}_{g}$ is the ground motion acceleration input.

With the aid of the SIMULINK module of MATLAB, a dynamical simulation system was developed, in which the Wen model [36] is utilized to simulate the restoring force curve of the steel frame structure, and the improved Graesser and Cozzarelli model presented above is used for NiTi SMA damper.

\section{Seismic Structural Control Using SMA Dampers}

In this section, to assess the effectiveness of the proposed recentering SMA dampers (RSMAD) in mitigating the seismic response of building structure, nonlinear time history analysis on a multistory steel frame with and without the dampers subjected to representative earthquake ground motions was performed. The improved Graesser and Cozzarelli model for RSMAD given in Section 3.3 was employed in this numerical study. A ten-story steel moment resisting 

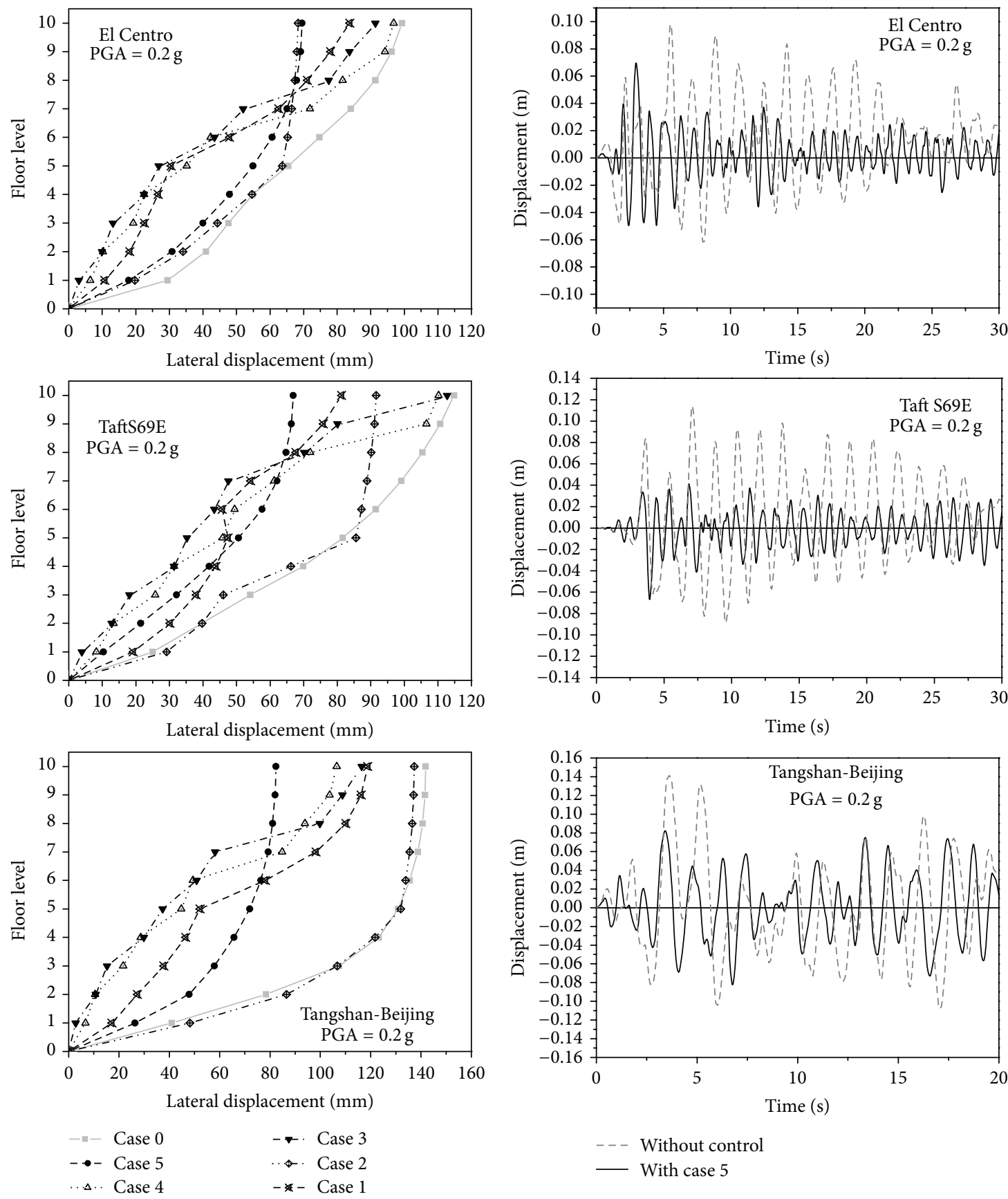

(a)

(b)

FIGURE 11: Lateral displacement envelopes (a) and roof displacement time histories (b) with and without SMA dampers under basic (moderate) ground motions.

frame structure was selected for this study. The building is designed for a location in Beijing, China. The parameters of the structure are listed in Table 2.

Three representative earthquake ground motions were used to considering the site effect. Three earthquake ground motions, namely, Imperial Valley 1940 El Centro, Lincoln School 1952 Taft, and Beijing Hotel 1976 Tangshan, were selected. These three ground motions represent different site conditions. According to Chinese code for seismic design of building [37], the local seismic precautionary intensity is eight degrees. The peak ground accelerations (PGA) were adjusted to $0.2 \mathrm{~g}$ and $0.4 \mathrm{~g}$ corresponding to a seismic hazard level of $10 \%$ and $2 \%$ probability of exceedance in a 50 -year period, respectively.

Simulation analysis is conducted on the bare structure and on the structure with five or ten SMA dampers installed as shown in Figure 10. Parameters of the SMA damper are listed as follows: $K_{0}=K_{d}=120 \mathrm{kN} / \mathrm{mm}, B_{c}=360 \mathrm{KN}$, 

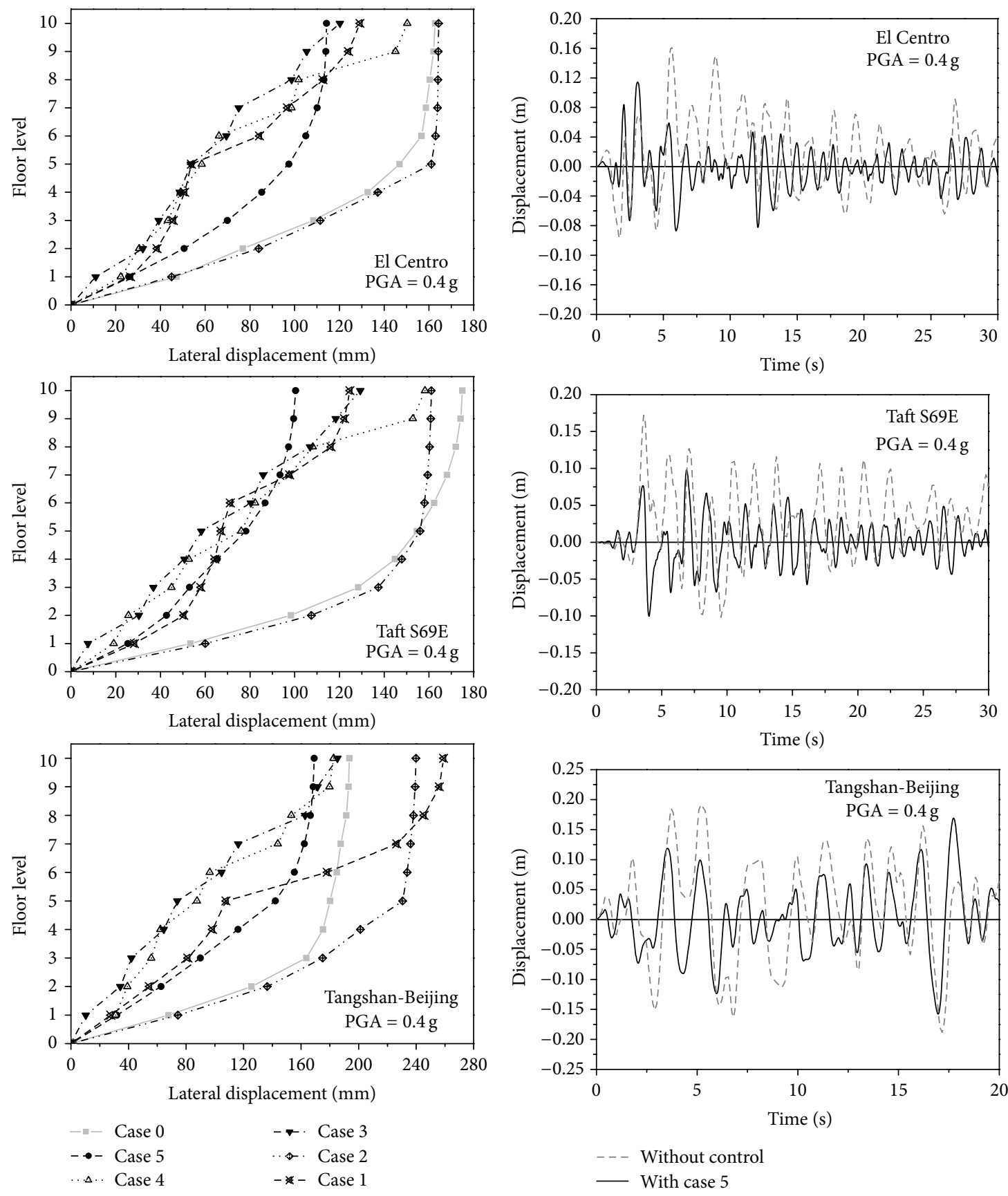

(a)

(b)

FIGURE 12: Lateral displacement envelopes (a) and roof displacement time histories (b) with and without SMA dampers under strong (severe) ground motions.

$\alpha=0.010, f_{T}=0.34, c=0.0001, a=2500, n=5$, $x_{\mathrm{Mf}}=0.015, f_{M}=100000$, and $m=3$.

Figures 11 and 12 show the lateral displacement envelopes with and without SMA dampers under basic ground motions $(0.2 \mathrm{~g})$ and strong ground motions $(0.4 \mathrm{~g})$, respectively. As we can see, for most cases, the lateral displacement of the structure decreases remarkably with the introduction of the SMA dampers. However, the location and the number of the dampers have significant effects on the control results. Case 5, in which dampers are installed in all stories, is the best for the overall structural vibration control. For other 4 configurations, in which five dampers are installed in different stores, cases 3 and 4 with dampers installed in alternate stories perform better than cases 1 and 2 with dampers placed in consecutive stories. Moreover, case 3 is better than case 4 since the first story is retrofitted. Case 1 is slightly worse due to the whiplash effect, and case 2 is the worst since the stiffness of the lower half is significantly greater than that of the upper half of the structure. The roof displacement time histories with (case 5) and without 
SMA dampers under basic ground motions ( $0.2 \mathrm{~g})$ and strong ground motions $(0.4 \mathrm{~g})$ are also, respectively, provided in Figures 11 and 12, which confirm that the SMA dampers significantly reduce the structural vibration.

\section{Concluding Remarks}

This paper presents the results of a study on evaluating the efficacy of using an innovative SMA-based damper to reduce the seismic response of structures. To describe the hysteresis behavior of the SMA damper, an improved Graesser and Cozzarelli model was proposed and verified by the cyclic tensile test on SMA wires.

Cyclic tests on the SMA damper model utilizing four superelastic SMA wires with $0.5 \mathrm{~mm}$ diameter with various prestrains under different loading frequencies and displacement amplitudes were carried out. The results show satisfying hysteresis properties, including both recentering and energy dissipating features under various conditions.

A comparative study on nonlinear time history analysis of the seismic response of a ten-story steel frame with the SMA dampers was performed. Five cases were considered for the location and the number of the dampers in the stories. The numerical analysis results indicate that the proposed SMA damper is capable of significantly reducing seismic response of structures, which verifies its effectiveness as energy dissipating device for structures. However, it is also indicated that the location and number have significant effects on the results of the response.

In future multiobjective optimization model will be proposed to obtain the number and the location of the SMA dampers and large scale shake table tests will be performed on a steel frame building with SMA dampers to prove the efficacy of these dampers in dissipating seismic energy.

\section{Acknowledgments}

This work was funded by National Science Foundation of China (no. 51108426 and no. 41104106), China Postdoctoral Science Foundation (no. 20100471008), and Research Fund for the Doctoral Program of Higher Education of China (no. 20104101120009). These supports are greatly appreciated. The opinions expressed in this study are those of the authors and do not necessarily reflect the views of the sponsor.

\section{References}

[1] H. N. Li and L. S. Huo, "Advances in structural control in civil engineering in China," Mathematical Problems in Engineering, vol. 2010, Article ID 936081, 23 pages, 2010.

[2] G. Song, N. Ma, and H. N. Li, "Applications of shape memory alloys in civil structures," Engineering Structures, vol. 28, no. 9, pp. 1266-1274, 2006.

[3] SEAOC Vision 2000 Committee, Performance-Based Seismic Engineering, Structural Engineering Association of California, Sacramento, Calif, USA, 1995.

[4] ATC-40, Seismic Evaluation and Retrofit of Conctete Buildings, Applied Technology Council, 1996.
[5] FEMA 273, NEHRP Guidelines for Seismic Rehabilitation of Buildings, Federal Emergency Management Agency, 1997.

[6] Y. Fujino, T. T. Soong, and B. F. Spencer Jr., "Structural control: basic concepts and applications," in Proceedings of the ASCE Structures Congress, pp. 15-18, Chicago, Ill, USA, April 1996.

[7] B. F. Spencer and S. Nagarajaiah, "State of the art of structural control," Journal of Structural Engineering, vol. 129, no. 7, pp. 845-856, 2003.

[8] T. T. Soong and G. F. Dargush, Passive Energy Dissipation Systems in Structural Engineering, John Wiley \& Sons, New York, NY, USA, 1997.

[9] F. M. Mazzolani, "Passive control technologies for seismicresistant buildings in Europe," Progress in Structural Engineering and Materials, vol. 3, no. 3, pp. 277-287, 2001.

[10] M. Dolce and D. Cardone, "Mechanical behaviour of SMA elements for seismic applications-part 2: austenite NiTi wires subjected to tension," International Journal of Mechanical Sciences, vol. 43, no. 11, pp. 2657-2677, 2001.

[11] H. N. Li and X. X. Wu, "Limitations of height-to-width ratio for base-isolated buildings under earthquake," The Structural Design of Tall and Special Buildings, vol. 15, no. 3, pp. 277-287, 2006.

[12] R. Desroches, J. McCormick, and M. A. Delemont, "Cyclic properties of superelastic shape memory alloy wires and bars," Journal of Structural Engineering, vol. 130, no. 1, pp. 38-46, 2004.

[13] T. W. Duerig, K. N. Melton, D. Stockel, and C. M. Wayman, Engineering Aspects of Shape Memory Alloys, Butterworth Heinemann, London, UK, 1990.

[14] K. Wilde, P. Gardoni, and Y. Fujino, "Base isolation system with shape memory alloy device for elevated highway bridges," Engineering Structures, vol. 22, no. 3, pp. 222-229, 2000.

[15] M. Dolce, D. Cardone, and R. Marnetto, "Implementation and testing of passive control devices based on shape memory alloys," Earthquake Engineering and Structural Dynamics, vol. 29, no. 7, pp. 945-968, 2000.

[16] M. Dolce, D. Cardone, F. C. Ponzo, and C. Valente, "Shaking table tests on reinforced concrete frames without and with passive control systems," Earthquake Engineering and Structural Dynamics, vol. 34, no. 14, pp. 1687-1717, 2005.

[17] M. Indirli, M. G. Castellano, P. Clemente, and A. Martelli, "Demo-application of shape memory alloy devices: the rehabilitation of the S. Giorgio Church Bell-Tower," in Smart Structures and Materials 2001: Smart Systems for Bridges, Structures, and Highways, vol. 4330 of Proceedings of SPIE, pp. 262-272, Newport Beach, Calif, USA, March 2001.

[18] B. Andrawes and R. Desroches, "Unseating prevention for multiple frame bridges using superelastic devices," Smart Materials and Structures, vol. 14, no. 3, pp. S60-S67, 2005.

[19] R. DesRoches and M. Delemont, "Seismic retrofit of simply supported bridges using shape memory alloys," Engineering Structures, vol. 24, no. 3, pp. 325-332, 2002.

[20] H. Li, M. Liu, and J. Ou, "Vibration mitigation of a stay cable with one shape memory alloy damper," Structural Control and Health Monitoring, vol. 11, no. 1, pp. 21-36, 2004.

[21] Y. Zhang and S. Zhu, "A shape memory alloy-based reusable hysteretic damper for seismic hazard mitigation," Smart Materials and Structures, vol. 16, no. 5, pp. 1603-1613, 2007.

[22] J. Ocel, R. DesRoches, R. T. Leon et al., "Steel beam-column connections using shape memory alloys," Journal of Structural Engineering, vol. 130, no. 5, pp. 732-740, 2004. 
[23] J. McCormick, R. Desroches, D. Fugazza, and F. Auricchio, "Seismic assessment of concentrically braced steel frames with shape memory alloy braces," Journal of Structural Engineering, vol. 133, no. 6, pp. 862-870, 2007.

[24] Y. M. Parulekar, G. R. Reddy, K. K. Vaze et al., "Seismic response attenuation of structures using shape memory alloy dampers," Structural Control and Health Monitoring, vol. 19, no. 1, pp. 102119, 2012.

[25] K. Tanaka, "A thermomechanical sketch of shape memory effect: one-dimensional tensile behavior," Res Mechanica, vol. 18, no. 3, pp. 251-263, 1986.

[26] C. Liang and C. A. Rogers, "One-dimensional thermomechanical constitutive relations for shape memory materials," Journal of Intelligent Material Systems and Structures, vol. 1, no. 2, pp. 207-234, 1990.

[27] L. C. Brinson, "One-dimensional constitutive behavior of shape memory alloys: thermomechanical derivation with non-constant material functions and redefined martensite internal variable," Journal of Intelligent Material Systems and Structures, vol. 4, no. 2, pp. 229-242, 1993.

[28] F. Falk, "Model free energy, mechanics, and thermodynamics of shape memory alloys," Acta Metallurgica, vol. 28, no. 12, pp. 1773-1780, 1980.

[29] Q. P. Sun and K. C. Hwang, "Micromechanics modelling for the constitutive behavior of polycrystalline shape memory alloysII: study of the individual phenomena," Journal of the Mechanics and Physics of Solids, vol. 41, no. 1, pp. 19-33, 1993.

[30] J. G. Boyd and D. C. Lagoudas, "A thermodynamical constitutive model for shape memory materials-part I: the monolithic shape memory alloy," International Journal of Plasticity, vol. 12, no. 6, pp. 805-842, 1996.

[31] Q. P. Sun and K. C. Hwang, "Micromechanics modelling for the constitutive behavior of polycrystalline shape memory alloysI: derivation of general relations," Journal of the Mechanics and Physics of Solids, vol. 41, no. 1, pp. 1-17, 1993.

[32] H. Qian, H. Li, G. Song, and W. Guo, "A constitutive model for superelastic shape memory alloys considering the influence of strain rate," Mathematical Problems in Engineering, vol. 2013, Article ID 248671, 8 pages, 2013.

[33] W. J. Ren, H. N. Li, and G. Song, "A one-dimensional strain-rate dependent constitutive model for superelastic shape memory alloys," Smart Materials and Structures, vol. 16, no. 1, pp. 191-197, 2007.

[34] E. J. Graesser and F. A. Cozzarelli, "Shape-memory alloys as new materials for aseismic isolation," Journal of Engineering Mechanics, vol. 117, no. 11, pp. 2590-2608, 1991.

[35] H. Özdemir, Nonlinear transient dynamic analysis of yielding structures [Ph.D. thesis], University of California, Berkeley, Calif, USA, 1976.

[36] Y. K. Wen, "Method for random vibration of hysteretic systems," Journal of the Engineering Mechanics Division, vol. 102, no. 2, pp. 249-263, 1976.

[37] GB, 50011-2010, Code for Seismic Design of Buildings, Ministry of Housing and Urban-Rural Development of the People's Republic of China, 2010. 


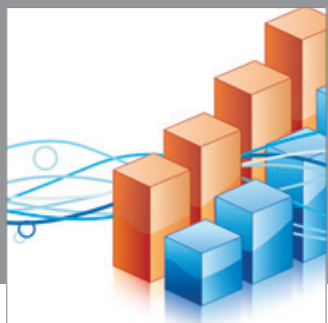

Advances in

Operations Research

mansans

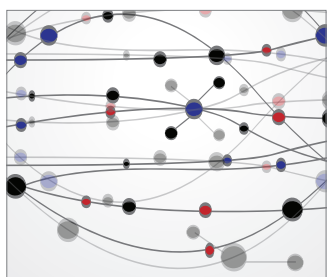

The Scientific World Journal
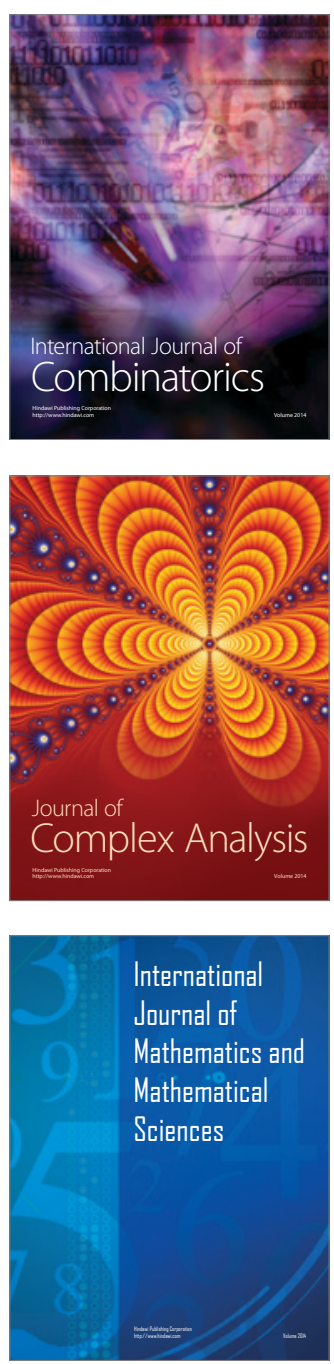
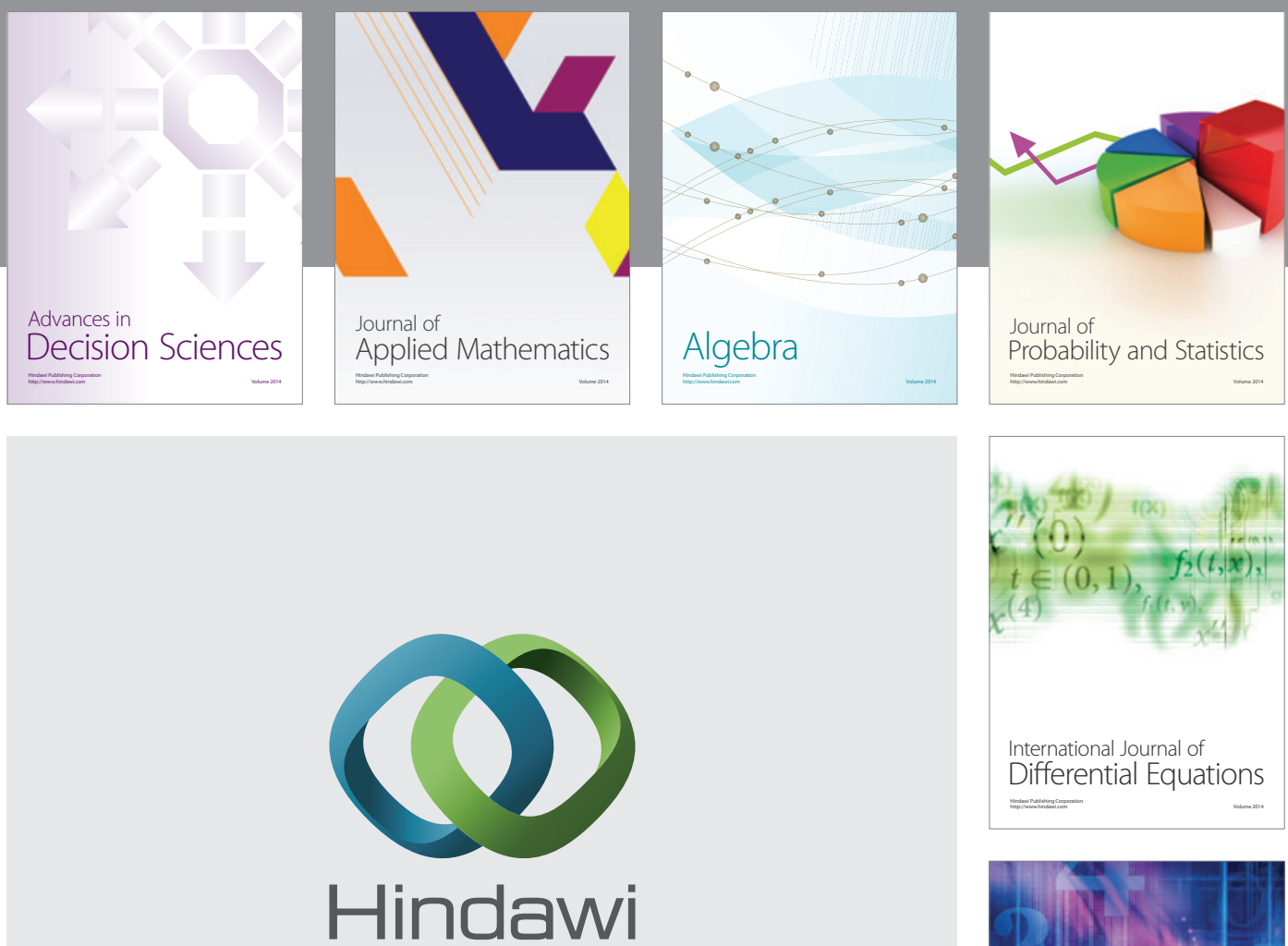

Submit your manuscripts at http://www.hindawi.com
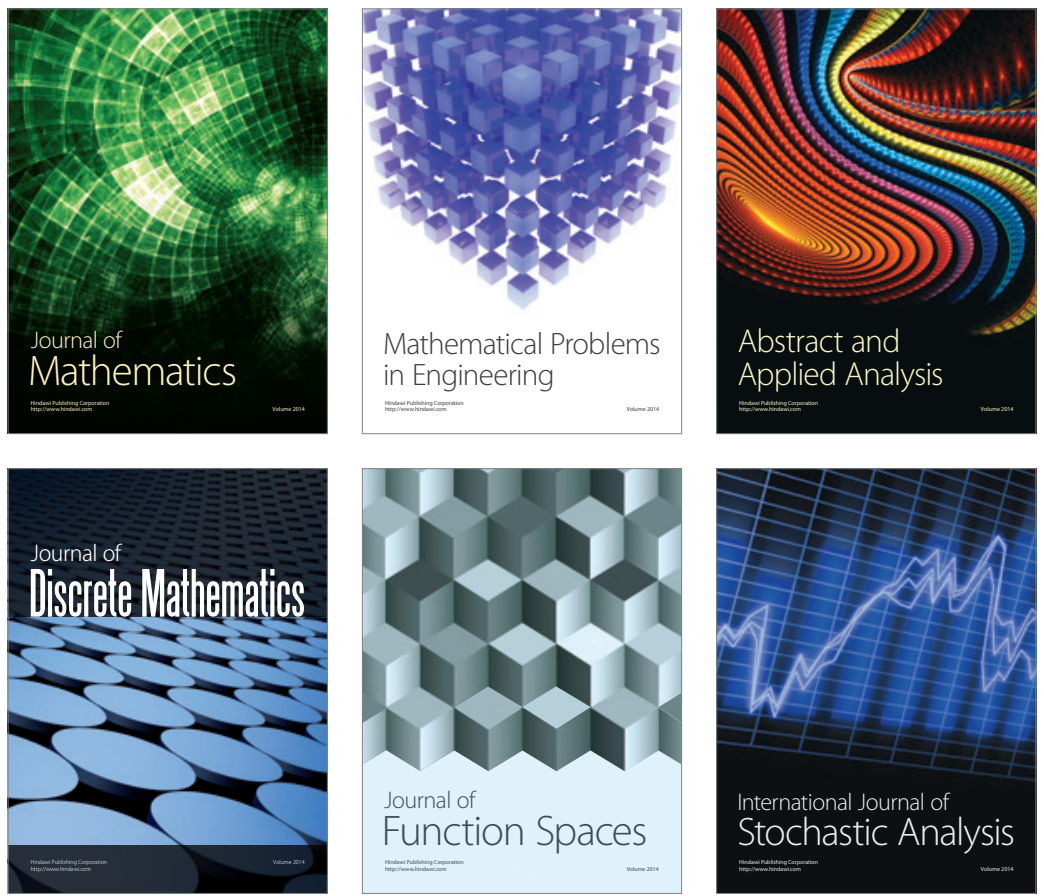

Journal of

Function Spaces

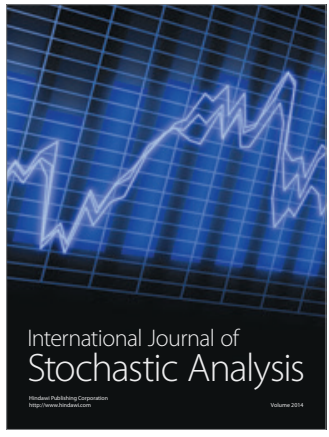

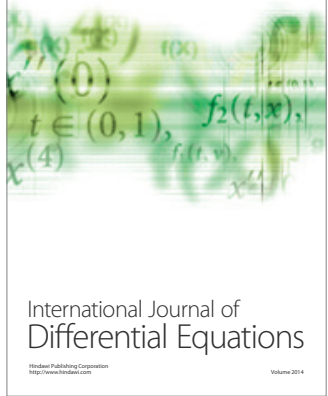
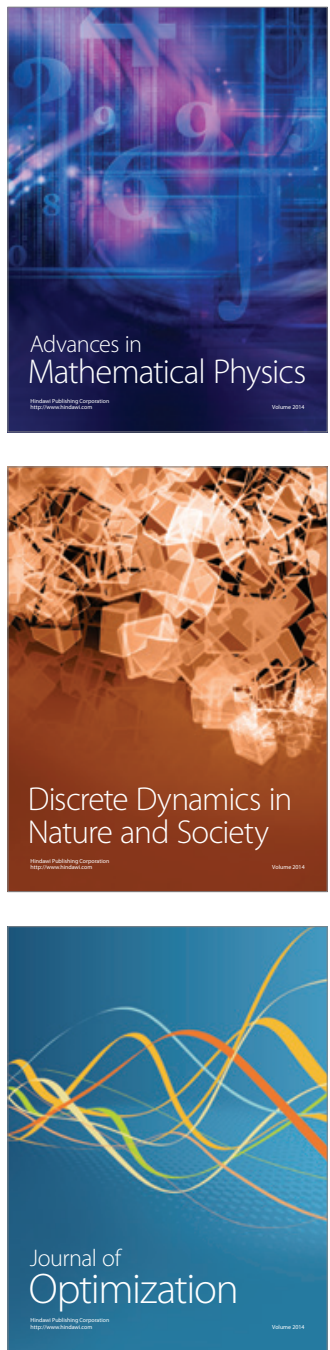